Doi: http://dx.doi.org/10.5212/OlharProfr.v.12i2.359378

\title{
O PODER DO RÍTMO NO ENSINO E NA APREN- DIZAGEM $^{1}$ \\ THE POWER OF RHYTHM IN TEACHING AND LEARNING
}

\author{
Katherine SMITHRIM* \\ Martha Maria PRATA-LINHARES ${ }^{* *}$
}

Resumo: $\mathrm{O}$ artigo reúne o fenômeno do ritmo, a formação de professores e o envolvimento dos alunos. O sentido de ritmo apresentado é muito mais amplo do que o sentido musical de ritmo. Inclui um senso de equilíbrio nos ritmos dos movimentos físicos, da mente, da aprendizagem, do corpo, das atividades e da energia. A pesquisa aqui relatada é dividida em duas partes. A primeira parte aborda o papel do ritmo na formação de professores na pedagogia Waldorf. A segunda analisa o ritmo nas salas de aula de educação infantil, em Ontário, no Canadá, e em Minas Gerais, Brasil. Na coleta e análise de dados as pesquisadoras canadense e brasileira utilizam um mesmo protocolo de observação para registrar o ritmo das atividades em sala de aula, tanto na agenda das atividades do dia quanto no registro das atividades rítmicas. Com o propósito de analisar a relação entre ritmo e envolvimento nas atividades, a investigação acontece em salas de aula em que o ritmo é um conceito fundamental, e em salas de aula que não dão atenção intencional ao ritmo. Um dos propósitos da investigação é mostrar como o ritmo interfere no envolvimento dos alunos nas atividades de aprendizagem, a necessidade do envolvimento das crianças para que elas possam aprender e dos professores para que tenham condições de criar ambientes que promovam a aprendizagem. Usar o ritmo para promover

\footnotetext{
${ }^{1}$ Pesquisa apoiada pelo Programa TEACH da Universidade de Queen's e pela Coordenação de Aperfeiçoamento de Pessoal de Nível Superior - CAPES .

* PhD em Música pela Eastman School of Music. E-mail: smithrik@educ.queensu.ca

${ }^{* *++}$ Doutora em Educação pela PUC-SP. E-mail: marthaml@terra.com.br
} 
O poder do rítmo no ensino e na aprendizagem

o envolvimento tem o potencial de transformar o ensino e a aprendizagem.

Palavras-chave: Ritmo. Envolvimento. Ensino-aprendizagem. Formação de professores.

Abstract: This paper brings together rhythm, teacher education and student engagement. The sense of rhythm shown is much broader than the musical sense of rhythm. Rather, it includes a sense of balance in the rhythms of physical movement, of the mind, of learning, of the body, of activities, and of energy. The research reported here is divided in two parts. The first part, regards the role of rhythm in Waldorf teacher education. The second examines the role of rhythm in primary school classrooms in Ontario, Canada and Minas Gerais, Brazil. In this second part of the study, the Canadian and Brazilian researchers use the same observational protocol to record the rhythms of classroom activity, both in the scheduling of the day and the rhythmic nature of the activities themselves. Researchers examine classrooms in which rhythm is a foundational concept as well as classrooms with no intentional attention to rhythm, in order to analyze the relationship between rhythm and engagement in learning. The research is designed to enable the researchers to show how rhythm affects student engagement in learning. Children must be engaged in order to learn. Teachers must be engaged in order to create an environment in which learning can take place. The use of rhythm can deepen engagement and has the potential to transform teaching and learning.

Keywords: Rhythm. Engagement. Teaching and Learning. Teacher education. 


\section{CONTEXTO}

Em Gana, na África Ocidental, uma das culturas agrícolas principais é o amido de milho. Cabe às mulheres o trabalho de moer o milho. Elas colocam o grão inteiro em uma pedra de grandes dimensões ou em uma tigela de madeira, o pilão. Os pilões podem ser utilizados por várias pessoas ao mesmo tempo; cada uma segura uma grande pá e vai batendo os grãos alternadamente, em um ritmo constante de batidas: levantar e socar, levantar e socar, levantar. Normalmente duas mulheres fazem esse trabalho, enquanto uma terceira mulher se agacha ao redor do pilão e move os grãos no intervalo das batidas. Se uma das mulheres que estão segurando a pá perder o rítmo, o pilão vira para o lado podendo machucar uma perna, e se a mulher que move os grãos perder o rítmo, seus dedos podem ser esmagados. Portanto, se houver perda do ritmo por qualquer uma das mulheres que executam o trabalho de moer o milho, alguém fica ferido.

Em nosso dia a dia temos poucas práticas como essa, em que o ritmo é tão obviamente crítico. Em Gana, no entanto, as pessoas consideram o desenvolvimento do sentido rítmico tão profundamente que nunca falam sobre isso. Faz parte de suas vidas desde a infância. Elas tratam o desenvolvimento do ritmo com o mesmo interesse que nós tratamos do desenvolvimento da linguagem falada. John Blacking (1973), um dos primeiros etnomusicólogos a fazer um estudo da música na África Central e Ocidental, comenta que em Venda, quando uma criança começa a bater com a sua colher no chão ou na mesa na hora da refeição, ninguém toma a colher ou diz "shh". Ao invés disso, todos os membros da família começam a tocar juntos, com suas colheres, e logo toda a família participa fazendo uma música ritmada que pode continuar por até trinta minutos.

Jogos de passar pedrinha são outra forma de treinamento do ritmo em Ghana. As crianças se ajoelham ou sentam-se em roda, cada uma com uma pedra em frente de si, e passam a pedra ao redor do círculo cantando e marcando o ritmo como no jogo brasileiro escravos de Jó. Uma canção para o jogo de passar pedrinha cantada pelas crianças de Ghana é a Boa Si Me Nsa, que quer dizer "a pedra bateu em minha mão vovó". (ADZENYAK, MARAIRE; TUCKER, 1997, p. 39, tradução nossa). Ainda que o ritmo esteja presente na infância em nossos países, Canadá e Brasil, e em muitas outras culturas, o desenvolvimento do senso rítmico não é considerado uma habilidade 
O poder do rítmo no ensino e na aprendizagem

vital. Parece-nos que o ritmo do trabalho, das brincadeiras e dos dias, estações e anos está ficando cada vez menos significativo.

Em seus escritos filosóficos, Dewey $(1934,1980)$ e Whitehead (1929) discutem o fenômeno do ritmo como fundamental à vida e à aprendizagem. Há aproximadamente oitenta anos, Alfred North Whitehead (1929), em seu ensaio intitulado The Rhythm of Education (O Ritmo na Educação), desenvolveu a teoria de que a falta de atenção ao ritmo e à natureza do crescimento mental foi a principal fonte da inexpressividade e desmotivação na educação. Ao falar do fracasso dos alunos para aprender, Whitehead (Ibid., p.32, tradução nossa) afirma que "não é porque as nossas tarefas são essencialmente muito difíceis" que os alunos não aprendem, mas "porque as nossas tarefas são definidas de uma forma não natural, sem ritmo e sem o estímulo do sucesso imediato, e sem concentração".

Neste artigo apresentamos uma investigação sobre o ritmo no ensino e na aprendizagem. Primeiramente contextualizamos a pesquisa e reportamos estudos das autoras e de colegas pesquisadores como Prata-Linhares (2003, 2008), Smithrim e Upitis, (2005), Upitis, Smithrim, Garbati e Ogden (2008), Smithrim e Chapman (2005), e na segunda parte apresentamos o projeto piloto internacional, envolvendo pesquisa de observação em salas de aula de Educação Infantil em Minas Gerais, Brasil, e em Ontário, Canadá.

Em uma pesquisa de oito anos, Smithrim e Upitis (2005) estudaram os efeitos de uma iniciativa nacional de artes nas escolas canadenses, sobre as atitudes dos estudantes em relação à escola e ao rendimento dos alunos. Examinaram concepções e práticas de cerca de mil professores, cem diretores e administradores, e cem artistas. A pesquisa também mostrou os efeitos dos programas de artes sobre o rendimento escolar para mais de 12.000 alunos.

O engajamento, ou envolvimento na aprendizagem, surgiu como uma das explicações do motivo de as crianças comprometidas com as iniciativas de artes terem pontuações significativamente maiores nos testes de matemática de cálculo e estatística do que os alunos em escolas de dois grupos de controle: as escolas com iniciativas na área de tecnologias e escolas sem iniciativas recentes. Para Smithrim e Upitis (2005) engajamento significa a sensação de estar totalmente envolvido. Esse termo vem da palavra francesa engagé, que quando usada para descrever escritores e artistas, quer dizer moralmente comprometido. É esse compromisso - físico, emocional, intelectual 
e social - que surgiu de forma consistente nos relatórios orais e escritos dos programas de artes destinados a alunos, professores, administradores, pais e artistas.

Quando Prata-Linhares (2003) estudou como a inclusão da arte em um programa de formação de professores de Educação Infantil e Ensino Fundamental no Brasil afetava o desenvolvimento profissional das professoras envolvidas, encontrou resultados semelhantes. As professoras que participaram do programa de formação em que a arte fazia parte sentiram-se mais envolvidas e comprometidas com as aprendizagens de seus alunos e demonstraram mais prazer nas atividades de ensino. Isso também foi observado em uma pesquisa posterior (ibid., 2008), com professores universitários.

Na pesquisa de Smithrim e Upitis (2005), muitos dos estudantes referiram-se ao estudo de artes como uma mudança na rotina. Eles relataram que sentiram prazer na liberdade de poder andar pela sala de aula, sair de suas cadeiras e participar de atividades em movimento. Surgiu, assim, a possibilidade de que talvez parte da energia presente nas artes pudesse estar relacionada aos diferentes ritmos na sala de aula, resultantes das atividades artísticas. Essa possibilidade despertou-nos o desejo de pesquisar sobre o ritmo no ensino e na aprendizagem.

\section{O RITMO NA EDUCAÇÃO WALDORF}

Para entender a questão do ritmo no ensino-aprendizagem, Smithrim e Chapman (2005) examinaram uma escola em que o ritmo era considerado fundamental ao ensino-aprendizagem, uma escola de educação Waldorf. Rudolf Steiner definiu o ritmo como sendo um dos princípios básicos da educação Waldorf. O conceito Waldorf com relação ao ritmo é muito mais amplo do que o significado musical de ritmo. Na verdade, o ritmo inclui um senso de equilíbrio entre os ritmos do movimento físico, da mente, da aprendizagem, do corpo, do dia, das atividades e da energia.

Desenvolvida por Steiner em 1919, a educação Waldorf tem como base uma abordagem de desenvolvimento que se volta para as necessidades da criança em crescimento e do adolescente a caminho da maturidade. Os professores Waldorf buscam transformar a educação em uma arte que educa a criança como um todo: o coração e as mãos, bem como a cabeça. Do ponto de vista Waldorf, a educação verda- 
O poder do rítmo no ensino e na aprendizagem

deira envolve o despertar das capacidades - a habilidade de pensar clara e criticamente, de experimentar com empatia e compreender fenômenos no mundo, distinguir o que é bonito, bom e verdadeiro. A professora da sala de aula caminha por uma trilha de descobertas com as crianças e as leva a uma compreensão do mundo dos significados, ao invés de levá-las ao mundo da causa e efeito. (CHILDS, 1991). O objetivo claro da educação Waldorf é "desenvolver indivíduos que são capazes de, por si próprios, dar significado às suas vidas". (RIVER SONG WALDORF SCHOOL, 2008, tradução nossa).

Na mesma época em que Alfred North Whitehead e John Dewey estavam escrevendo e proferindo palestras sobre a importância do ritmo na aprendizagem na América do Norte, Steiner estava fazendo palestras a professores em Dornach, na Alemanha, em 1919. Mesmo tendo bastante influência no desenvolvimento da educação progressiva na América do Norte, as ideias de Whitehead e Dewey sobre ritmo não resistiram aos ventos de mudança na educação pública no Canadá. Em decorrência dessa mudança, seria possível participar de uma conferência da Sociedade Canadense para Estudos e Educação (Canadian Society for Studies in Education-CSSE) que contasse com a presença de muitos dos professores educadores de todo o Canadá, e não ouvir sequer uma vez a palavra ritmo. No Brasil, a situação é semelhante. Quando se menciona a palavra ritmo, ela está normalmente associada ao tempo que alguém leva para aprender alguma coisa, ou ao ritmo na música. Todavia, seria praticamente impossível conversar com um(a) educador(a) Waldorf sobre ensino-aprendizagem, por mais de cinco minutos, sem que ele(a) mencionasse o ritmo.

Smithrim e Chapman (2005) apresentaram um interesse particular sobre a questão de como professores Waldorf iniciantes chegam à compreensão da importância do ritmo. A pesquisa inicial teve seu ponto de partida no programa de educação para professores no Centro Rudolf Steiner, em Richmond Hill, Ontario, Canadá. As pesquisadoras observaram e participaram durante uma semana do programa de formação de professores e deram sequência a essas observações com entrevistas individuais com docentes e entrevistas com grupos focais de alunos/professores. Pelo fato de terem ido pesquisar o ritmo, elas viam e ouviam ritmo em cada momento do primeiro dia, desde o barulho das serras penetrando a madeira resistente na aula de carpintaria, até os versos falados acompanhados por movimento, tais como: 
Katherine SMITHRIM; Martha Maria PRATA-LINHARES loco,)

Straight as a spear I stand, (Firme como uma lança eu me coStrong are my arms and legs, (Meus braços e pernas são fortes,) amor.)

Warm is my heart with love. (Meu coração se aquece de

Mas esses eram ritmos óbvios, ritmos superficiais. A estrutura rítmica profunda da educação Waldorf se aninhava, camada sobre camada, iniciando na filosofia fundamental. Dos dez fundamentos rítmicos que elas relatam, quatro são relevantes ao nosso trabalho: inspirando e expirando, ritmo do dia, ritmo das festas e ritmo da semana.

\section{INSPIRANDO E EXPIRANDO}

"Inspirando e Expirando" é a metáfora que os professores Waldorf usam para se referir às necessidades dos alunos por uma educação de ritmo equilibrado, uma experiência de "entrada" e uma "saída" por meio de formas de expressão artísticas e outras. Na educação infantil, por exemplo, ouvir alguém contando uma história é uma atividade de entrada, que seria seguida de uma atividade de saída como cantar. Para entender tal conceito, você, leitor(a), poderia inspirar cinco vezes sem expirar entre cada inspiração. Essa sensação apertada, contraída é como nos sentimos se nossa atividade for totalmente inspiração, sem nenhuma atividade expressiva de expiração. Atividades como ouvir alguém contando uma história, seguir instruções, ler e resolver um problema de matemática são geralmente atividades de inspiração, enquanto que movimento físico, conversar, cantar e arrumar o ambiente são atividades de expiração. As professoras planejam as aulas e os dias letivos mantendo o foco no equilíbrio da inspiração e expiração. Essa metáfora é a terminologia do dia-a-dia das Escolas Waldorf.

\section{RITMO DO DIA}

O dia de aula começa com um verso de abertura e outros exercícios iniciais, que muitas vezes envolvem movimento físico. O restante da manhã é a aula principal. Os blocos de aula principal consistem de trabalho em uma única área por duas horas cada dia, 
O poder do rítmo no ensino e na aprendizagem

por um período de três ou quatro semanas. Ciências, matemática, estudos sociais e a arte das línguas são ensinados nesses blocos de aula principal. Habilidades que precisam de prática diária, tais como música e alguns elementos de matemática, são incluídas todos os dias. Outras disciplinas, tais como euritmia ${ }^{2}$, pintura, artesanato, música e segunda e terceira línguas, são designadas para o período da tarde.

\section{RITMO DAS FESTAS}

As festas, comemorações, são um componente importante da vida escolar das escolas Waldorf. A escola inteira se reúne para observar eventos significativos e épocas do ano, começando com a cerimônia de boas-vindas aos alunos do primeiro ano e à comunidade escolar. As escolas Waldorf celebram muitas festas sazonais com histórias, canções, teatro, procissões e comida. Essas festas servem para unir os alunos e as famílias aos ritmos da natureza e do cosmos. Todas têm suas próprias tradições, muitas das quais foram adaptadas de culturas antigas (por exemplo, dançar ao redor do mastro em primeiro de maio).

\section{RITMO DA SEMANA}

Principalmente na sala de aula dos principiantes, cada dia da semana tem uma sensação ou caráter distinto. Cada dia tem a sua própria cor, lanche, e atividades específicas. O tempo é um conceito abstrato para uma criança pequena; assim, as professoras oferecem oportunidades para as crianças viverem as diferentes experiências dos dias da semana, como fez a professora educadora que deu a seguinte sugestão aos docentes: "Crie o ritmo para as crianças. Depois de algum tempo, as crianças acordam e dizem 'é dia de sopa'; elas não dizem 'é quarta-feira'." Uma professora-aluna disse que "a segunda-feira é sempre um pouco mais maluquinha do que as terças ou as quartas, as sextas também, há uma expiração antes do final de semana, e assim há os ritmos semanais de tudo o que é ensinado. Quando isso acontece? Uma vez por semana, por exemplo".

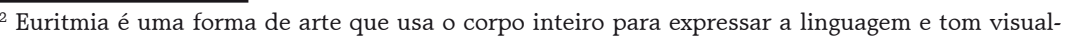
mente. 


\section{RITMO DOS TRÊS DIAS}

O ritmo dos três dias é constituído por procedimentos pedagógicos que as professoras utilizam quando introduzem conteúdo novo, quer seja um conceito científico, uma história ou uma música. No primeiro dia, as crianças observam ou experimentam alguma coisa, no segundo dia elas descrevem o que foi observado e no terceiro dia elas explicam. Alguns professores educadores Waldorf usam as palavras encontro, experiência e conceito para explicar tal processo. Esse ritmo dos três dias se assemelha à teoria de Alfred North Whitehead sobre o ritmo na educação. De acordo com Whitehead (1929), existe um ritmo de aprendizagem e três etapas fundamentais nos processos de desenvolvimento na educação: o romance, que é a evocação do interesse; a precisão, que é a aquisição de técnica; e a generalização, que envolve o prazer do sucesso. Uma das falhas das escolas, na experiência de Whitehead, é que o desenvolvimento escolar era geralmente limitado ao segundo estágio, o da precisão, da aquisição de técnicas.

O referido teórico afirmava que sem essas três etapas pouca aprendizagem real, duradoura, aconteceria: "a não ser que os alunos estejam continuamente sustentados pela evocação do interesse, da aquisição de técnicas, e do prazer do sucesso, eles nunca apresentarão progresso, e certamente perderão o interesse". (Ibid., p. 60).

Smithrim e Chapman (2005) relataram que até o último mês do programa de formação dos professores Waldorf iniciantes, os alunos/professores chegaram a uma real e profunda compreensão do papel do ritmo no ensino e aprendizagem. Eles perceberam o poder do ritmo em suas próprias vidas, alcançaram uma boa compreensão das necessidades rítmicas das crianças e entenderam o poder do ritmo como uma estratégia de manejo de classe. Também alcançaram uma compreensão específica de como as crianças aprendem e entenderam a questão de como usar o ritmo em áreas de assuntos diferentes. Eles sabiam quando o ritmo estava "certo" e quando não estava. Entenderam a importância do ritmo na vida familiar da criança e compreenderam que os ritmos de sala de aula geram um sentimento de segurança nas crianças. Assim, entenderam o papel fundamental do ritmo na pedagogia Waldorf. 
O poder do rítmo no ensino e na aprendizagem

\section{O RITMO EM SALAS DE AULA DE EDUCAÇÃO INFANTIL}

Com alguma compreensão dos fundamentos rítmicos na educação para professores Waldorf, nós, autoras deste artigo, Katharine e Martha, queríamos examinar como a compreensão desses ritmos é operacionalizada nas salas de aula Waldorf. O propósito do estudo realizado no Brasil e no Canadá é examinar as maneiras em que o ritmo se manifesta em salas de aula Waldorf e não-Waldorf. As perguntas diretivas da pesquisa são as seguintes:

1-De que maneiras e formas o fenômeno do ritmo está presente em salas de educação infantil?

2-Como a atenção ao ritmo influencia na montagem dos horários, o currículo e atividades de ensino-aprendizagem em salas de educação infantil?

3-Como as estratégias rítmicas se relacionam com o comprometimento dos alunos?

\section{COLETA DE DADOS}

Enquanto Martha estava no Canadá, ela e Katharine observaram uma sala de educação infantil Waldorf, com crianças de 4 e 5 anos, durante dois dias inteiros. Posteriormente, no Brasil, Martha fez observações em uma classe de crianças de 4 e 5 anos, em uma escola particular que enfatiza a criatividade. Essa escola tem também um programa de formação de professores em que as artes são de grande importância. Martha escolheu-a porque pensou que nessa instituição escolar o sentido do ritmo seria forte. Em sua obra Qualitative research and evaluation methods, Patton (2002) refere-se à etapa de seleção de informação e apresenta casos ricos dos quais é possível aprender muita coisa sobre questões de importância central ao propósito da pesquisa, como seleção proposital. Nesse meio tempo, no Canadá, Katharine estendeu sua pesquisa a uma sala de educação infantil e uma de $2^{\circ}$ ano em uma escola Waldorf localizada em outra cidade, bem como uma de educação infantil e uma de $2^{\circ}$ ano em uma escola não-Waldorf. Katharine escolheu a escola não-Waldorf a fim de aguçar sua capacidade de observação por meio do contraste. Nessa escola específica não-Waldorf, as crianças da educação infantil estavam aprendendo a ler e escrever. Katharine antecipou que ali haveria menos atenção ao 
ritmo do que nas escolas Waldorf. Ela passou dois dias consecutivos fazendo observações em cada uma das quatro salas.

Em todos os casos, no Brasil e no Canadá, as observações foram gravadas como notas de campo diretamente em um computador do tipo laptop. Um relatório com anotações das horas era mantido junto ao relatório da atividade e ao item relativo ao nível do envolvimento geral. Assim, anotávamos as atividades que as crianças faziam, a hora em que iniciavam e terminavam cada atividade e se estavam envolvidas. Nessa pesquisa piloto, nós não usamos uma escala de comprometimento ou envolvimento, embora já tivéssemos examinado duas dessas escalas: uma adaptação do método de amostragem por experiência (ESM) de Csikszentmihalyi (1993), utilizado por Custodero (1998), e a escala de envolvimento Leuven para crianças pequenas [LIS-YC] (Laevers, 1996). Percebemos que nos estágios iniciais da observação, nós precisávamos nos concentrar em perceber as estruturas rítmicas na sala de aula e os níveis gerais de envolvimento, em vez de nos concentrarmos nas atividades individuais de crianças, que a escala exige.

\section{DESCOBERTAS COM RELAÇÃO AO RITMO}

\section{RITMO DO DIA}

Todas as classes seguiam um cronograma planejado. Na educação infantil não-Waldorf, e em ambas as classes de nível dois, Waldorf e não-Waldrof, rever o cronograma do dia era parte da conversa inicial da roda. Na escola do Brasil, os participantes da pesquisa pouco falavam sobre o cronograma daquele dia, mas, sim, conversavam sobre o dia anterior, sobre o que os alunos fizeram e como fizeram o registro, ou se lembravam disso. Normalmente os alunos faziam o registro em forma de desenho e este era pendurado na parede, para que, no final da semana, eles pudessem ver o que haviam realizado a cada dia.

Em algumas classes, as transições de uma atividade para a outra foram suaves, enquanto que em outras, tanto na Waldorf como na não-Waldorf, toda a atividade parou enquanto a professora captou a atenção de todos os alunos. Nos casos em que a atividade parou por mais de alguns segundos, enquanto as crianças tinham que ficar sentadas ou paradas em um lugar por alguns minutos, esperando até 
O poder do rítmo no ensino e na aprendizagem

que todos os colegas se aproximassem ou ficassem quietos, observamos como as crianças rapidamente arrumavam outra atividade para preencher o vazio da espera.

\section{INSPIRADO E EXPIRANDO}

Em todas as classes, diferentes tipos de atividades seguiam uma à outra ao longo do dia. Nas salas de aula Waldorf, havia muito mais exemplos de variedade dentro de cada atividade. Era evidente que a professora estava alternando atividades em que as crianças deviam ficar mais introspectivas com atividades expressivas, criando assim o ciclo inspiração e expiração. Por exemplo, em uma sala do $2^{\circ}$ ano, na aula de matemática, as crianças iniciaram com uma atividade de arremesso de bola em que a professora estava no centro do círculo e jogava a bola para cada criança por vez. As outras crianças contavam "cinco, dez, quinze, vinte..." a cada vez que uma nova criança pegava a bola, como se a professora tivesse acrescentado cinco cada vez que jogava a bola à outra criança. Em seguida as crianças sentaram e escreveram a tabuada de cinco no seu caderno de lição com lápis colorido. Primeiramente fizeram uma margem em torno da página, e em seguida, usando um lápis de cera retangular, fizeram linhas horizontais largas, coloridas, como guia de espaçamento entre cada linha da tabuada. Assim que terminavam o trabalho no caderno, as crianças iam individualmente pegar seu tricô e começavam a tricotar. A progressão partiu da atividade de arremesso de bola envolvendo o físico e o vocal, em direção a uma atividade artística em que as crianças estavam sentadas. Em seguida veio a escrita da tabuada, depois o movimento de andar para pegar o tricô, sentar novamente e, em silêncio, trabalhar com as mãos.

Em uma das classes não-Waldorf as crianças estavam sentadas em pequenos grupos fazendo atividades do livro, e as professoras diziam coisas como "Continue trabalhando, quando você terminar é tempo livre". Nessas classes, o trabalho era normalmente no livro, e uma mudança de ritmo era oferecida pelo intervalo, educação física, música, lanche, almoço e tempo livre. Veja, por exemplo, este planejamento de um dia para uma sala não-Waldorf de $2^{\circ}$ ano:

9h10min Francês

9h40min Matemática

370 Olhar de professor, Ponta Grossa, 12(2): 359-378, 2009.
Disponível em <http://www.uepg.br/olhardeprofessor> 


$\begin{array}{ll}\text { 10h10min } & \text { Intervalo } \\ \text { 10h40min } & \text { Educação Física } \\ \text { 11h20min } & \text { Educação Física } \\ \text { 12hoOmin } & \text { Almoço } \\ \text { 13h10min } & \text { Escrita } \\ \text { 13h40min } & \text { Música } \\ \text { 14h20min } & \text { Escrita criativa } \\ 15 \text { hOOmin } & \text { Tempo livre } \\ 15 \text { h30min } & \text { Encerramento }\end{array}$

Dentro do ritmo regular da sala, houve momentos em que o ritmo não mudou mesmo quando as crianças obviamente não estavam envolvidas e precisavam de uma mudança.

Na educação infantil no Brasil, Martha observou que cada dia começava com uma roda. No início do tempo da roda, as crianças estavam sempre envolvidas. Normalmente, após nada mais do que 15 minutos, elas se distraíam e apenas algumas ainda prestavam atenção àquilo que a professora dizia. A professora queria ouvir todas as histórias das crianças, histórias sobre elas mesmas, ou coisas que tinham feito, e queria que todas as crianças também ouvissem. No entanto, essa atividade extrapolou a capacidade de concentração e escuta das crianças. Em uma das fotos da roda, tiradas para fins da pesquisa, nem uma criança, a não ser a que estava conversando com o professor, estava visivelmente envolvida.

\section{RITMO VISUAL}

As salas de aula Waldorf que visitamos estavam permeadas de ritmo. Começamos a pensar no senso de ordem proposital, como sendo visualmente rítmico. Observamos muitos exemplos de ritmo visual nas salas de aula, como o pendurar um tecido por sobre uma luz fluorescente e a maneira como as toalhas de mão estavam penduradas. Porém, o mesmo não foi observado nas escolas não Waldorf.

Momentos rítmicos aconteciam como ondas nas salas de aula Waldorf. Canções rítmicas e movimento corporal rítmico se alternavam a esforço silencioso e concentrado durante o dia no ciclo de inspiração e expiração. As crianças ficavam de pé e repetiam "Firme como uma lança eu me coloco" e em seguida se dirigiam a suas carteiras para uma meia hora de concentração em uma atividade de desenho. Assim que 
O poder do rítmo no ensino e na aprendizagem

cada criança acabava, ele ou ela começava a tricotar ou fazer crochê até que os outros terminassem. Em seguida todos ficavam de pé e recitavam a tabuada de sete usando um ritmo corporal que envolvia um modelo de bater palmas, bater o pé e bater na coxa. Dessa forma, as atividades rítmicas estavam encaixadas dentro da sucessão rítmica de inspirar e expirar ao longo do dia. Não percebemos esse tipo de equilíbrio proposital de atividade concentrada e expressiva nas salas de aula não-Waldorf. No entanto, os níveis de envolvimento entre as salas Waldorf e não-Waldorf não foram tão óbvios ou tão diferentes quanto esperávamos.

\section{DESCOBERTAS COM RELAÇÃO AO ENVOLVIMENTO}

\section{BRINCADEIRA LIVRE}

Na educação infantil da escola Waldorf e na do Brasil, as crianças estavam completamente envolvidas no tempo livre para brincadeiras. Brincavam individualmente e em pequenos grupos. Muitas vezes suas brincadeiras envolviam uma história criada, com muita improvisação de objetos de cenário e vestimentas. Percebemos que as crianças, por si só, criavam atividades de inspiração e expiração dentro do tempo livre para brincadeira. No seguinte fragmento de transcrição de vinte minutos, a garotinha identificada como "G" muda de atividade a cada um ou dois minutos.

10h30min - G estende um lenço no chão e começa a pular como um coelhinho

1Oh33min - G descansa no chão

10h34min - G movimenta-se com o lenço, estendendo-o com cuidado no chão. Sobe de lado no cavalinho de balance e em seguida volta para o lenço no chão,

10h35min - deita-se para descansar, traseiro voltado para cima, e em seguida sobe no cavalinho de balanço

10h36min - G fica balançando no cavalinho de balanço

10h38min - G retorna ao lenço verde no chão e coloca um prendedor na ponta. Ela está agindo de forma possessiva com relação ao lenço. Assistindo à outra atividade, diz "Ribbit ribbit" de vez em quando, pega outro lenço rosa, coloca-o ao lado do verde, em seguida pega um de cor malva e coloca-o do outro lado do verde, um de tom malva mais escuro ao final, um de cor turquesa na mesma ponta. Tira uma cadeira do caminho. 
10h41min - De joelhos, olhando outras crianças moendo farinha, em seguida fica chateada porque alguém colocou um banco sobre seu edredom de lenços. Ela conserta seu edredom de lenços e diz "Eu tenho que arranjar um milhão de panos", ainda arrumando seus panos.

10h45min - G diz baixinho "Não pise na minha casa. Você está destruindo minha casa. Agora eu vou ter que fazer tudo de novo". Senta quietinha, olhando os outros. Faz de conta que está comendo alguma coisa (um bloquinho de madeira) sentindo a textura de cada bloco, esfregando cada um em sua bochecha.

10h48min - G deita sobre sua casa de lenços, ainda esfregando os blocos de madeira na bochecha, agora sentindo o bloco na mão e no queixo e deitando de costas com os joelhos dobrados.

10h50min - A garota rola de lado, levanta e sobe os degraus para contar à professora que as outras crianças ficam destruindo sua casa. A professora diz a ela que fale para as crianças não correrem por cima de sua casa, então ela fica de pé no centro da sala e diz, em voz tão suave que as outras crianças não ouvem, "parem de correr em cima da minha casa".

Enquanto a criança observada acima necessitava de frequentes mudanças de atividade, outras crianças estavam desenvolvendo atividades que as mantinham envolvidas durante dez ou quinze minutos de uma vez.

Ainda percebemos que as crianças espontaneamente criavam e participavam de atividades rítmicas durante seu tempo livre. Em duas salas de educação infantil Waldorf, no momento separado para limpeza (depois da sessão de tempo livre), observamos algo muito bonito. As crianças, em duplas, estavam guardando os pedaços compridos de tecido colorido. Uma criança segurava cada ponta, e ficavam bem distantes uma da outra se o tecido era comprido, quase da largura da sala. Elas diziam as palavras "sacudir, sacudir, dobrar" vagarosamente e ritmicamente enquanto dobravam o tecido. Depois elas sacudiam o tecido, jogando-o para cima como uma grande onda, duas vezes (sacudir, sacudir) e em seguida andavam em direção uma da outra. Uma criança pegava todas as pontas superiores, a outra se abaixava para pegar as pontas inferiores do tecido (dobrar) e elas faziam sacudir, sacudir, dobrar, outra vez. Provavelmente um professor deve ter mostrado a essas crianças como fazer isso em um momento anterior, mas ninguém lhes sugeriu que dobrassem o tecido de forma rítmica, como fizeram. 
O poder do rítmo no ensino e na aprendizagem

\section{FANTASIA}

As crianças da educação infantil no Brasil estavam sempre envolvidas quando a professora fazia uso da fantasia. Quando a professora usava fantoches ou uma boneca específica para falar com as crianças, todas elas ficavam totalmente envolvidas. Martha descreve esses momentos de fantasia como "momentos mágicos" na sala de aula.

\section{A HORA DA HISTÓRIA}

Tanto no Brasil como no Canadá, outra atividade em que as crianças ficavam altamente envolvidas era a contação de história. Crianças de 4 a 8 anos de idade sentavam-se e ouviam, embevecidas, toda a contação da história. No entanto, se a professora interrompia o ritmo da história fazendo perguntas, ou fazendo algum comentário sobre a as ilustrações, a atenção das crianças oscilava rapidamente. Observamos esse fenômeno tanto no Brasil como no Canadá.

Muitas professoras estão adotando técnicas interessantes de contação de histórias, tais como pedir às crianças que adivinhem o que vai acontecer na próxima página, chamar sua atenção para aquilo que estão vendo nas ilustrações, a fim de aumentar a qualidade das experiências das crianças com a literatura. O que observamos é que interrupções na contação da história, na verdade, diminuem a atenção. Pensamos que esse fenômeno merece estudo posterior.

\section{FESTAS E COMEMORAÇÕES}

Uma celebração de Páscoa aconteceu durante o período que em Martha estava observando a escola no Brasil. Na escola observada, todos os anos, na época da Páscoa, as professoras fazem uma relação da Páscoa com transformação e montam a celebração com base na palavra transformação. A escola inteira participou dos workshops que compreenderam vários tipos de transformação. Atividades dessa comemoração envolveram fazer biscoitinhos, pintar, cantar e modelar com massinha. Martha percebeu que as crianças estavam mais engajadas durante as atividades das comemorações do que quando estavam nas atividades normais da rotina escolar. A atividade de massinha, por exemplo, era uma atividade que envolvia várias faixas etárias, e 
o envolvimento das crianças foi total. A pesquisadora percebeu que as crianças criavam ritmos musicais distintos na maneira em que amassavam e moldavam a massinha.

\section{COMPORTAMENTOS ENGAJADOS}

Tanto no Brasil como no Canadá, observamos crianças que não estavam envolvidas com a tarefa que tinham em mãos, criando uma atividade que as mantinham envolvidas sem atrapalhar muito.

Martha anotou como um menino criou algo interessante para fazer enquanto estava sentado na roda. Ele estava mascando chiclete, então tirou um pedaço da boca, fez dele uma bolinha e colocou-a no olho esquerdo. Em seguida fez a mesma coisa novamente e colocou a bolinha no seu olho direito. Finalmente, ele fez um rolinho com outro pedaço, colocou-o no nariz e fez de conta que estava usando óculos. A professora não percebeu a atividade do garoto, pois sua atenção estava voltada para a criança que estava falando, por ser sua vez.

Lori Custodero (2006) tem observado crianças em muitos programas de música para crianças pequenas e constatado que muitas vezes o que nós acreditamos ser um comportamento indesejável, ou uma tarefa paralela, nada mais é do que uma tentativa de envolvimento da criança com o tópico que está sendo trabalhado. Ela não está tentando se livrar de determinadas aprendizagens, ou voltar as costas a determinados conhecimentos, mas está construindo uma maneira de fazer com que a tarefa fique mais interessante e, consequentemente, mais envolvente para ela. O garoto que a Martha observou parecia estar construindo uma maneira que permitiria que ele suportasse a atividade que estava acontecendo já por muito tempo.

Outro ótimo exemplo aconteceu na educação infantil Waldorf que Katharine observava. Era o momento silencioso do lanche e a aveia era o grão do dia. Uma garotinha não gostava de aveia e não tinha comido. Ela conseguiu atrair a atenção do garoto na ponta da mesa, apontou para a aveia e fez um sinal de negativo com o polegar. O adulto em frente dela disse: "Eu não quero ver nenhum dedão". A garotinha imediatamente escondeu o dedão e começou a fazer de tudo sem ele. Ela bebeu a água com os dedões dobrados e, a seguir, dobrou seu guardanapo e passou sua tigela sem usar os dedões. Algum tempo atrás, Katharine teria pensado que a garotinha estava sendo insolente, mas ao observar cuidadosamente a cena, percebeu que ela 
O poder do rítmo no ensino e na aprendizagem

não estava, na verdade, importando-se com a reação do adulto, ou até mesmo das outras crianças. A garotinha estava em uma viagem solo de descoberta sobre como fazer as coisas sem deixar os dedões aparecerem. Como ela não gostava de aveia, não queria comer, e não podia conversar, criou uma atividade para se manter envolvida, caladinha, enquanto estava à mesa. Como professora, Katharine poderia até pensar que o comportamento da criança fosse ameaçador, mas de sua posição privilegiada de observadora ela pôde perceber nesse comportamento uma nova possibilidade - a de que a criança estava tentando manter-se envolvida na atividade, criando um desafio para si própria.

\section{RITMO E ENVOLVIMENTO}

Das análises dos dados observados, aprendemos que para fazer uma relação do envolvimento com as estruturas rítmicas na sala de aula, seria necessário adaptar dois tipos de observação simultânea. Um pesquisador precisa registrar a atividade da sala de aula com o máximo de detalhes possível, enquanto outros observadores mapeiam o envolvimento de alunos individuais usando uma escala de envolvimento como a do protocolo observacional de Custodero (1998), ou a escala de envolvimento para crianças pequenas de Leuven (Laevers, 1996). Usar tais escalas em uma variedade de salas de aula pode revelar uma relação direta e positiva entre ritmo e envolvimento. $\mathrm{O}$ estabelecimento de tal relação mostraria que usar o ritmo para aprofundar o envolvimento tem o potencial de transformar o processo de ensino e aprendizagem. surgiram:

Dessa pesquisa piloto, ampliações abriram-se e novas questões

- Alguns dos fundamentos rítmicos na educação Waldorf são transferíveis a outros contextos de aprendizagem?

- Quando as crianças não estão envolvidas em uma determinada atividade de sala de aula, há alguma razão para continuar a atividade sem uma mudança no modo ou ritmo?

- Quando é que um mau comportamento de uma criança, ou uma tarefa paralela pode ser entendido(a) como uma tentativa de se tornar ou se manter envolvida?

- Os programas de formação de professores incluem considerações rítmicas ou fundamentos? Se isso acontece, como é feita essa inclusão? 
Assim deixamos, através das perguntas acima, um convite provocativo para a continuidade deste trabalho em outras pesquisas.

\section{REFERÊNCIAS}

ADZENYAH, A. K., MARAIRE, D.; TUCKER, J. C. Let your voice be heard: songs from Ghana and Zimbabwe. Danbury, CT: World Music Press, 1997.

BLACKING, J. How musical is man? Seattle: University of Washington Press, 1973.

CHILDS, G. Steiner education in theory and practice. Edinburgh: Floris Books, 1991.

CUSTODERO, L. Observing flow in young children's music learning. General Music Today, 12(1), 1998, 21-27.

Singing practices in 10 families with young children. Journal of Research in Music Education.2006; 54: 37-56

CSIKSZENTMIHALYI, M.; K. RATHUNDE. The measurement of flow in everyday life: Towards a theory of emergent motivation. In: JACOBS, J. E. (Ed.) Nebraska symposium on motivation, Vol. 40: Developmental perspectives on motivation. Lincoln: University of Nebraska Press,1993, p. 60.

DEWEY, J. Experiência e natureza: Lógica - a teoria da investigação: a arte como experiência: vida e educação: teoria da vida moral. Tradução de Murilo O. R. P. Leme, Anísio S. Teixeira e Leônidas G. de Carvalho. São Paulo/BRA: Abril Cultura, 1980. (Coleção Os Pensadores). (trabalho original publicado em inglês em 1934)

LAEVERS, F. (Ed.). The leuven involvement scale for young children LISYC manual. Experiential Education Series n.1. Leuven, Belgium: Centre for Experiential Education, 1996.

PATTON, M. Q. Qualitative research and evaluation methods (3rd ed.).Thousand Oaks, CA: Sage, 2002.

PRATA-LINHARES, M. M. O sentido da arte na formação continuada de professores de ensino fundamental: uma contribuição mágica. Dissertação de Mestrado. São Paulo: Programa de Pós-Graduação em Educação: Currículo, da Pontifícia Universidade Católica de São Paulo, 2003, 140p.

. Arte na especialização em docência universitária: contribuições para a formação de professores. In: $32^{\circ}$ REUNIÂO ANUAL DA ANPED: SOCIEDADE, CULTURA, EDUCAÇÃO - NOVAS REGULAÇÕES? Outubro 2009, Caxam- 
O poder do rítmo no ensino e na aprendizagem

bú. Disponível em: <http://www.anped.org.br/reunioes/32ra/arquivos/ trabalhos/GT24-5875--Int.pdf>. Acesso em: O4 out. 2009.

RIVER SONG WALDORF SCHOOL. What is unique about Waldorf education? How is it different from other alternatives (public schooling, Montessori, unschooling, etc.). Fort Collins, Colorado, 2008. Disponível em: <http:// www.fortnet.org/rsws>. Acesso em: 01 out. 2008.

SMITHRIM, K.; CHAPMAN, C. Rhythm in the turning: a case study of rhythm in Waldorf teacher education. Paper presented at Holistic Learning: Breaking New Ground, OISE/UT Toronto, Canadá, 2005.

SMITHRIM, K.; UPITIS, R. Learning through the arts: lessons of engagement. Canadian Journal of Education, 289 (182), 2005, 109-127.

UPITIS, R; SMITHRIM, K.; GARBATI, J.; OGDEN, H. The Impact of artmaking in the university workplace. International Journal of Education $\mathcal{E}$ the Arts, 9(8), 2008. Disponível em: <http://www.ijea.org/v9n8/>. Acesso em: 10 dez. 2008.

WHITEHEAD, A. N. The aims of education. New York: MacMillan, 1929.

Enviado em: 08/09

Aceito em: 12/09

378 Olhar de professor, Ponta Grossa, 12(2): 359-378, 2009.

Disponível em <http://www.uepg.br/olhardeprofessor> 